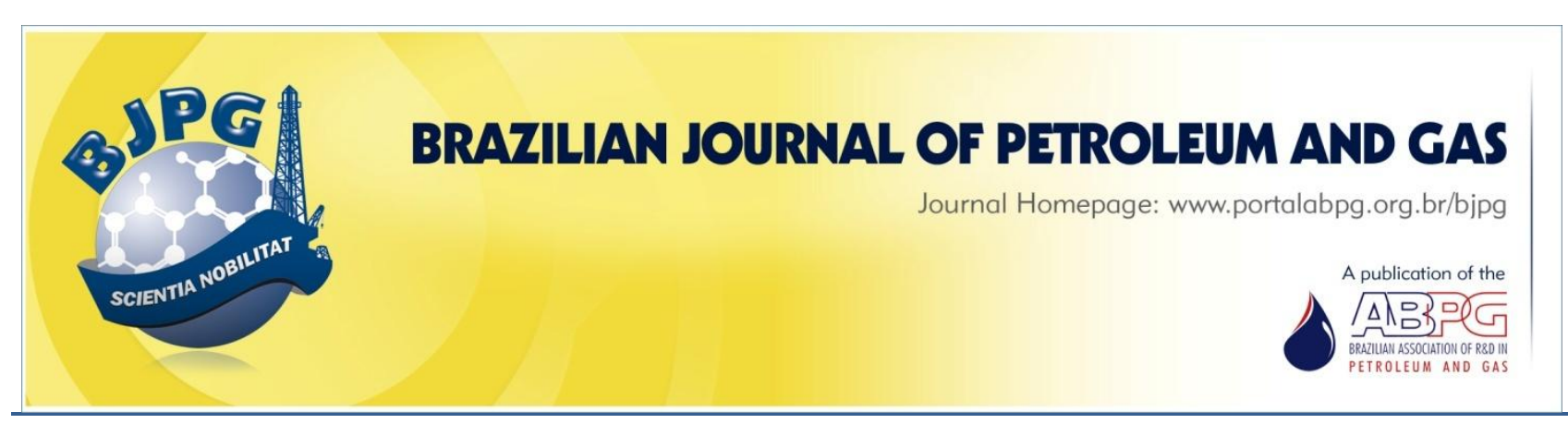

\title{
CHARACTERIZATION AND RHEOLOGICAL BEHAVIOR OF VARIOUS PAKISTANI CRUDE OILS
}

\author{
${ }^{a}$ Ahmad, M.; ${ }^{a}$ Amin, A.; ${ }^{a}$ Abdullah; ${ }^{b}$ Akram, M. S.; ${ }^{a}$ Usman, M. R. ${ }^{1}$ \\ ${ }^{a}$ Institute of Chemical Engineering and Technology, University of the Punjab, New Campus, Pakistan \\ ${ }^{b}$ Department of Chemical Engineering, COMSATS Institute of Information Technology, Pakistan
}

\begin{abstract}
Six Pakistani crude oils are characterized and their rheological behavior is studied in a standard rotational rheometer. TBP distillation data and density of whole crude oil are used to perform the basic characterization and to obtain the product distribution of the crudes. All the crude oils studied exhibit non-Newtonian behavior under the conditions of experimentation. Various non-Newtonian models such as the power law model, Bingham plastic model, and Herschel-Bulkley model are used to fit the experimental rheological data. The power law model exhibiting pseudoplastic behavior is found extremely satisfactory for the majority of the crude oils.
\end{abstract}

\section{KEYWORDS}

Pakistani crude oil; characterization; rheology; power law; Bingham plastic; Herschel-Bulkley

\footnotetext{
${ }^{1}$ To whom all correspondence should be addressed.

Address: Institute of Chemical Engineering and Technology, University of the Punjab, New Campus, Lahore 54590, Pakistan | Phone/Fax: +924299230462/+924299231159 | e-mail: mrusman.icet@pu.edu.pk doi:10.5419/bjpg2015-0009
} 


\section{INTRODUCTION}

Evaluating crude oils for determining the quality and possible amounts of its distillate and residue fractions is of great importance and is crucial for designing corresponding refinery and for exporting or importing crude oil. Knowing the true boiling point (TBP) distillation (boiling range) data, and density of a crude oil, various physical properties of the crude oil can be determined and the potential yields of the straight-run products can be worked out (Fahim et al., 2010).

The rheological properties of a crude oil are important in many aspects. These are important in all processes in which the crude oil is transported from one point to another (Ghannam et al., 2012). The information regarding the fluid type (Newtonian or non-Newtonian) and the flow characteristics are useful in pipeline sizing, pump selection, and handling and meeting storage requirements of the crude oil (Zhang \& Liu, 2008; Hemeida, 1990). Rheological measurements may be used to categorize and compare various crude oils (Dealy, 1979).

In the present study, six crude oils of Pakistani origins are evaluated using the given information of their density (of the whole crude) and true boiling point distillation data. The various properties of the crude oils are determined and their potential for providing various straight-run products is evaluated. Moreover, the rheological properties of these crudes are measured experimentally, and rheograms of the samples are fitted with various suitable non-Newtonian flow models.

\section{MATERIALS AND METHODS}

Six crude oil samples of Pakistani origins were obtained from OGDCL (Oil and Gas Development Company Limited). The true boiling point distillation data along with the density for each of the crude oils was also provided by OGDCL. The experimental TBP and density data of crudes, as received, is listed in Table 1. The experimental data was used to develop the basic characterization of crudes by calculating their specific gravity (API), average boiling points, characterization factor, correlation index, hydrogen to carbon atomic ratio, and kinematic viscosities at $37.8^{\circ} \mathrm{C}$ and $98.9{ }^{\circ} \mathrm{C}$. The details of the calculations are given in the next section. The rheological properties of the crude oils were measured using a Rheotec RC20 rotational rheometer. The rheometer had the provision of using either the cone-and-plate or plate-and-plate configuration. The rheometer was equipped with an optical encoder and not with a mechanical

Table 1. TBP and density data of the crude oils as received.

\begin{tabular}{|c|c|c|c|c|c|c|c|c|c|c|c|}
\hline \multicolumn{2}{|c|}{$\begin{array}{c}\text { Chanda } \\
\rho=831.4 \mathrm{~kg} / \mathrm{m}^{3}\end{array}$} & \multicolumn{2}{|c|}{$\begin{array}{c}\text { Dakhni } \\
\rho=757.7 \mathrm{~kg} / \mathrm{m}^{3}\end{array}$} & \multicolumn{2}{|c|}{$\begin{array}{c}\text { Dhupri } \\
\rho=872.2 \mathrm{~kg} / \mathrm{m}^{3}\end{array}$} & \multicolumn{2}{|c|}{$\begin{array}{c}\text { Dhurnal } \\
\rho=816.3 \mathrm{~kg} / \mathrm{m}^{3}\end{array}$} & \multicolumn{2}{|c|}{$\begin{array}{c}\text { Khaur } \\
\rho=846.3 \mathrm{~kg} / \mathrm{m}^{3}\end{array}$} & \multicolumn{2}{|c|}{$\begin{array}{c}\text { Toot } \\
\rho=778.5 \mathrm{~kg} / \mathrm{m}^{3}\end{array}$} \\
\hline Vol\% & $T^{\circ} \mathrm{C}$ & Vol\% & $T^{\circ} \mathrm{C}$ & Vol\% & $T^{\circ} \mathrm{C}$ & Vol\% & $T^{\circ} \mathrm{C}$ & Vol\% & $T^{\circ} \mathrm{C}$ & Vol\% & $T^{\circ} \mathrm{C}$ \\
\hline 2.14 & 45.0 & 3.53 & 45.0 & 0.49 & 45.0 & 1.82 & 45.0 & 38 & 45.0 & .74 & 45.0 \\
\hline 5.96 & 0.0 & 08 & 70.0 & 34 & 70.0 & 5.65 & 70.0 & 68 & 70.0 & .17 & 70.0 \\
\hline 11.73 & 5.0 & 15.07 & 95.0 & 4.94 & 95.0 & 10.00 & 95.0 & 4.49 & 95.0 & 14.96 & 95.0 \\
\hline 19.05 & 0.0 & 27.46 & 120.0 & 8.45 & 120.0 & 17.60 & 120.0 & 55 & 120.0 & .42 & 120.0 \\
\hline 25.94 & 5.0 & 36.09 & 145.0 & 11.79 & 145.0 & 24.99 & 145.0 & 14.43 & 145.0 & 34.10 & 145.0 \\
\hline 29.32 & 0.0 & 42.41 & 160.0 & .07 & 160.0 & 8.30 & 160.0 & 17.70 & 160.0 & 38.49 & 160.0 \\
\hline 31.52 & 0.0 & 45.22 & 170.0 & 15.60 & 170.0 & 31.00 & 170.0 & 19.71 & 170.0 & 40.90 & 170.0 \\
\hline 37.72 & 5.0 & 52.92 & 195.0 & 19.66 & 195.0 & 36.40 & 195.0 & 24.99 & 195.0 & 47.65 & 195.0 \\
\hline 44.96 & 220.0 & 58.69 & 220.0 & 24.40 & 220.0 & 41.34 & 220.0 & 29.14 & 220.0 & 55.57 & 220.0 \\
\hline 49.58 & 3.3 & 69.48 & 243.3 & 35.20 & 243.3 & 51.35 & 243.3 & 37.28 & 243.3 & 68.36 & 243.3 \\
\hline 57.48 & 270.0 & 73.72 & 0.0 & 40.24 & 0.0 & 5.52 & 70.0 & 46.48 & 70.0 & .15 & 270.0 \\
\hline 66.23 & 295.0 & 79.55 & 295.0 & 48.52 & 295.0 & 61.93 & 295.0 & 51.87 & 295.0 & 74.20 & 295.0 \\
\hline 70.99 & 320.0 & 83.55 & 320.0 & 55.02 & 320.0 & 66.91 & 320.0 & 57.53 & 320.0 & 78.27 & 320.0 \\
\hline 73.52 & 345.0 & 86.60 & 345.0 & 60.57 & 345.0 & 71.01 & 345.0 & 62.64 & 345.0 & 81.41 & 345.0 \\
\hline 76.77 & 371.1 & 89.62 & 371.1 & 65.96 & 371.1 & 75.41 & 371.1 & 67.34 & 371.1 & 84.63 & 371.1 \\
\hline
\end{tabular}


transducer, so the torque was measured without any deflection. The crude oil sample was placed in the gap between the stationary plate and the moving cone/plate after adjusting the temperature (using a circulating silicon oil bath) and the distance between the stationary plate and the moving cone/plate. The possible types of measurements were: a) rotational measurement with controlled shear rate (CSR) and b) rotational measurement with controlled shear stress (CSS). In the present study, all the experimental data was measured under the controlled shear stress method and the following steps were followed in carrying out the rheological measurements: calibration (the rheometer was calibrated to check for accuracy), program settings, sample loading, running the rheometer, and saving the results.
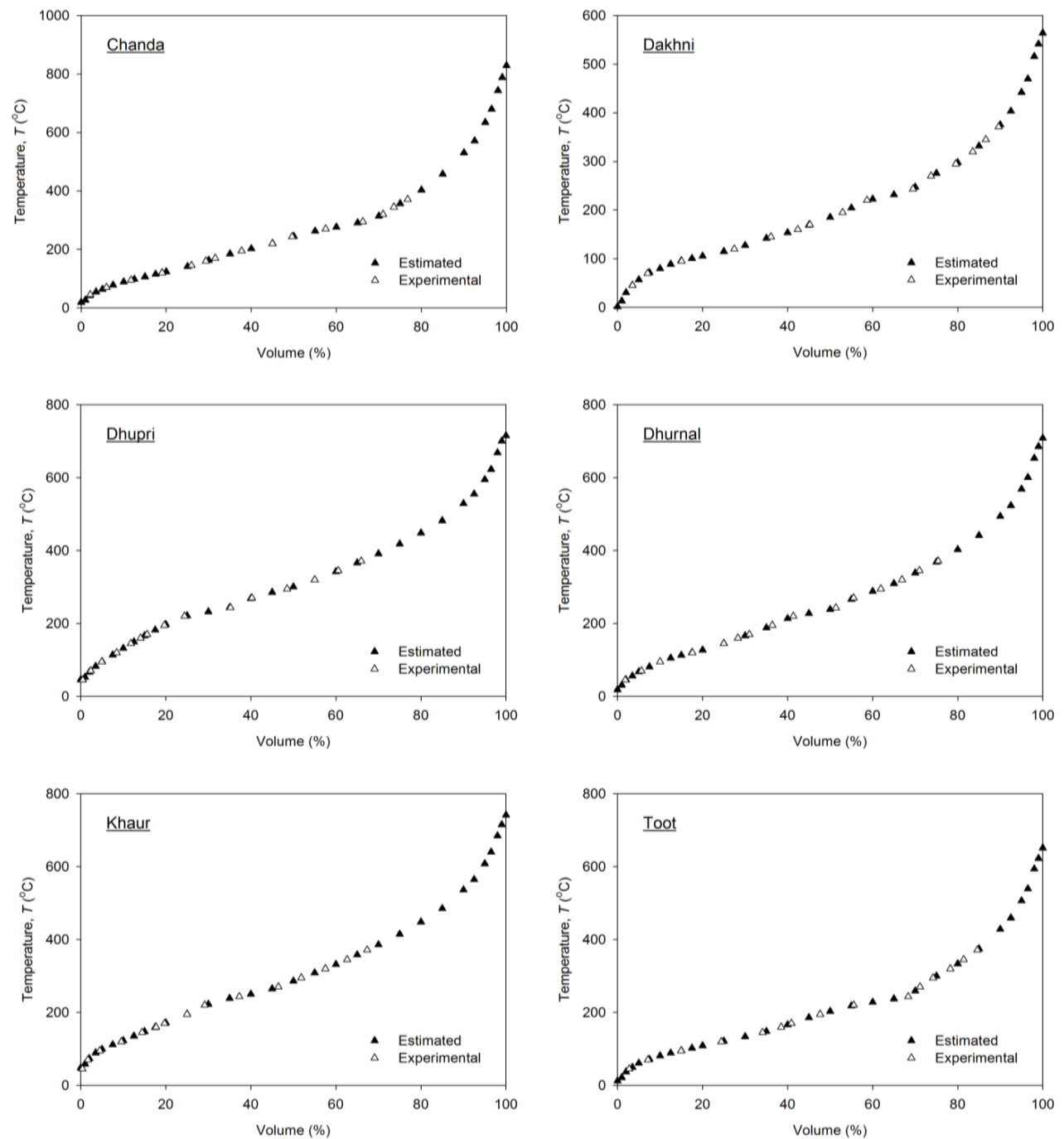

Figure 1. The experimental and estimated (extrapolated) TBP distillation curves of various crude oils of Pakistani origins. 
Aspen HYSYS of all crudes are shown in Figure 1 and the cut plot distributions, obtained from Aspen HYSYS, for the defined temperature ranges are shown in Table 2 and Figure 2. In each case, to find the average boiling points and, hence, the other

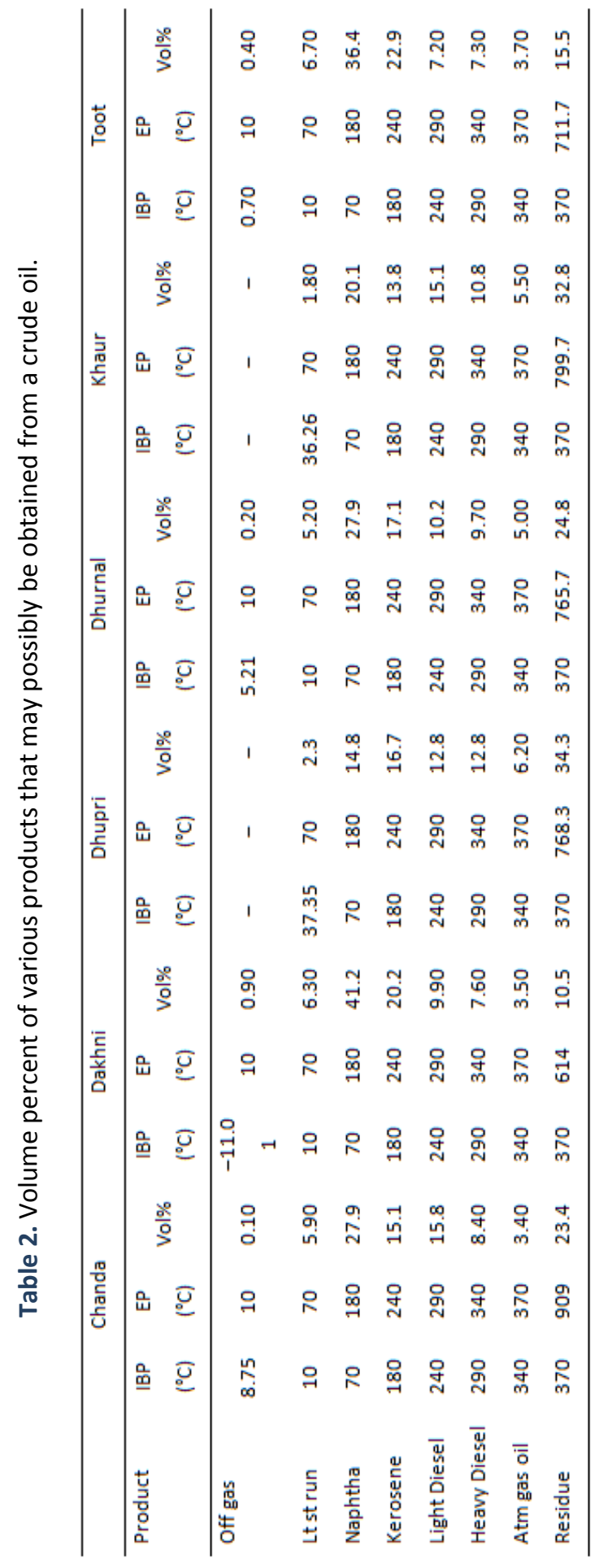

characterizing properties, the TBP curve was divided into 50 pseudocomponents. Using the information such as mole fraction, normal boiling point (NBP), and molecular weight (MW) of each pseudocomponent given by Aspen HYSYS, the molal average boiling point (MABP), cubic average boiling point $(C A B P)$, and mean average boiling point $(M e A B P)$ were calculated by applying equations 1, 2, and 3, respectively (Chang et al. 2012). For the molecular weight of each pseudocomponent, the Twu correlation was selected in Aspen HYSYS.

$M A B P=\sum\left(x_{i} \cdot(N B P)_{i}\right)$

Where both $M A B P$ and $N B P$ are in $\mathrm{K}$.

$C A B P=\left(\sum\left(x_{v i} \cdot(N B P)_{i}^{1 / 3}\right)\right)^{3}$

Where both $C A B P$ and $N B P$ are in $\mathrm{K}$.

$M e A B P=\frac{M A B P+C A B P}{2}$

Where $M e A B P, M A B P$, and $C A B P$ are in $\mathrm{K}$.

The characterization factor, correlation index $(C l)$, hydrogen to carbon atomic ratio, and kinematic viscosities, at $37.8{ }^{\circ} \mathrm{C}$ and $98.9{ }^{\circ} \mathrm{C}$, are calculated using Eq. 4, Eq. 5 (Speight, 2014), Eq. 6, and Eq. 7 (Riazi, 2005), and Eq. 8 and Eq. 9 (Riazi, 2005), respectively.

$K_{W}=\frac{(1.8 M e A B P)^{\frac{1}{3}}}{S G}$

Where $M e A B P$ is in $\mathrm{K}$ and $S G$ is the specific gravity at $15.6^{\circ} \mathrm{C} / 15.6^{\circ} \mathrm{C}$.

$C I=\frac{48640}{M e A B P}+473.7 S G-456.8$

Where $M e A B P$ is in $\mathrm{K}$ and $S G$ is at $15.6^{\circ} \mathrm{C} / 15.6^{\circ} \mathrm{C}$.

$$
\begin{aligned}
& C H=8.7743 \times 10^{-10}\left[\operatorname { e x p } \left(7.167 \times 10^{-3} M e A B P+\right.\right. \\
& \left.\left.+30.06242 S G-7.35 \times 10^{-3} M e A B P \times S G\right)\right] \times \\
& \times M e A B P^{-0.98445} S G^{-18.2753}
\end{aligned}
$$

Where $M e A B P$ is in $\mathrm{K}$ and $S G$ is at $15.6^{\circ} \mathrm{C} / 15.6^{\circ} \mathrm{C}$. 


$$
H C=\frac{11.9147}{C H}
$$

$\log v_{99}=-0.463634-0.166532(A P I)+$

$+5.13447 \times 10^{-4}(A P I)^{2}-8.48995 \times 10^{-3} K_{W}(A P I)+$

$+\frac{8.0325 \times 10^{-2} K_{W}+1.24899(A P I)+0.197680(A P I)^{2}}{A P I+26.786-2.6296 K_{W}}$

$\log v_{38}=4.39371-1.94733 K_{W}+0.127690 K_{W}^{2}+$ $+3.2629 \times 10^{-4}(A P I)^{2}-1.18246 \times 10^{-2} K_{W}(A P I)+$

$+\frac{0.17161 K_{W}^{2}+10.9943(A P I)}{A P I+50.3642-4.78231 K_{W}}+$

$+\frac{9.50663 \times 10^{-2}(A P I)^{2}-0.860218 K_{W}(A P I)}{A P I+50.3642-4.78231 K_{W}}$
The physical properties of the crude oils calculated above are shown in Table 3.

From the cut plot distribution shown in Figure 2, it is observed that both Dakhni and Toot crude oils contain the highest amounts of light products (light straight-run gasoline and naphtha) and the lowest amounts of residue. On the other hand, Dhupri and Khaur crude oils contain the highest amounts of residue and the lowest amounts of the light products as expected, since both Dhupri and Khaur crude oils are medium crude oils as shown in Table 3.

\subsection{Rheological behavior}

The results of the rheological measurements are shown in Figures 3 and 4 . Figure 3 shows the shear
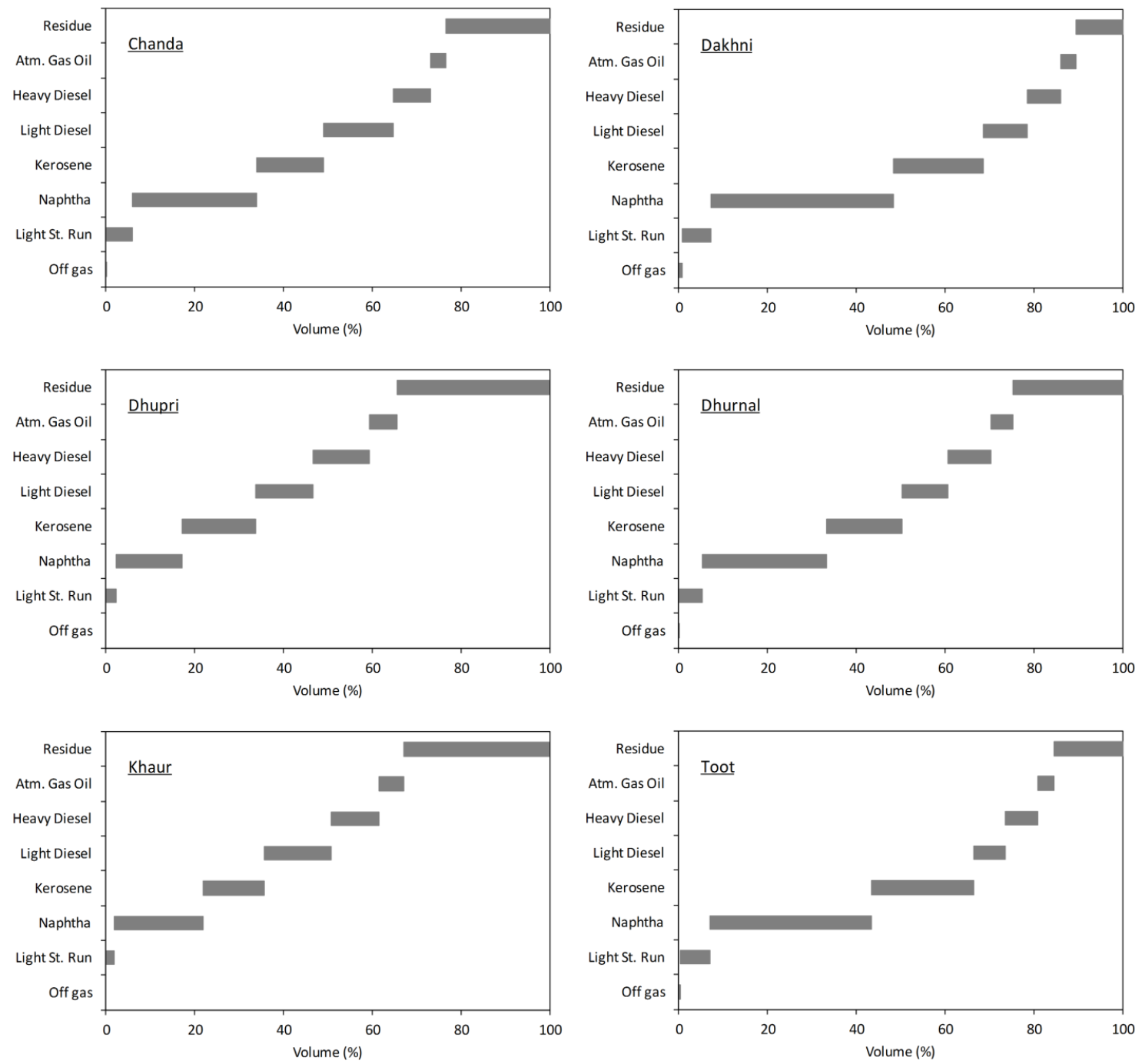

Figure 2. Estimated yields of various straight run products from various crude oils of Pakistani origins. 
stress and shear rate relationships (rheograms) of the crude oils. It is clear from the rheograms that, under the conditions of experimentation, none of the crude oils is Newtonian in nature. Instead, all of the crude oils follow a non-Newtonian behavior. It

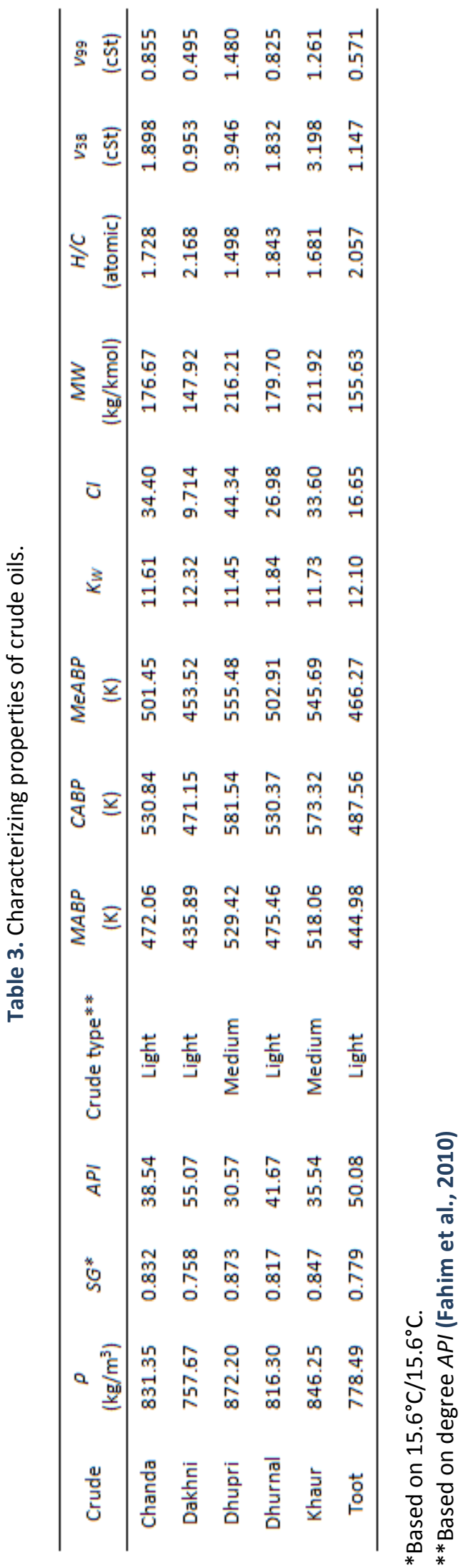

is also observed from Figure 3 that four of the crude oils studied, namely, Chanda, Dakhni, Dhurnal, and Toot have shown similar trends, i.e., in each case the curve starts right from the origin (no yield stress, which is a characteristic behavior of the Bingham plastic fluids) and the slope of the curve decreases continuously, which is a characteristic behavior of shear thinning or pseudoplastic fluids. The other two crude oils, namely, Dhupri and Khaur have shown different shear stress-shear rate behavior. For each of these crudes, the shear rate develops only after a certain value of the shear stress, known as yield stress, and after the point of yield stress the two crudes have shown different rheological behavior. For the Khaur crude oil, the curve shows a linear increase of shear stress with shear rate after reaching the point of yield stress. This type of behavior is described as Bingham plastic. The Dhupri crude oil, on the other hand, shows a behavior that is intermediary between those of the pseudoplastic and Bingham plastic fluids. After exhibiting a certain yield stress, the curve is not linear but the behavior is similar to a pseudoplastic fluid.

Figure 4 shows the change in apparent viscosity of the crude oils as a function of shear rate. The apparent viscosities of the crude oils were automatically measured by the rheometer. Initially, the apparent viscosity sharply decreases with an increase in shear rate and the viscosity rate decreases continuously afterwards. The case of the Khaur crude oil is observed to be a little different, for the viscosity virtually remains constant after an initial steep decrease. Hemeida (1990) has also found that the apparent viscosity decreases with shear rate for some crude oils studied in his/her work.

The experimental rheological data of shear stress-shear rate was fitted with a suitable nonNewtonian model. Various non-Newtonian models were used for this purpose. The power law or Oswald de Waele model, Herschel-Bulkley model, and Bingham plastic model were fitted to find the best-fit model and the corresponding model parameters. Table 4 gives the equations for each of these models.

In fitting a model to the experimental data, model shear stress values were obtained and compared with the experimental shear stress values. In each case, the following objective function was therefore minimized: 

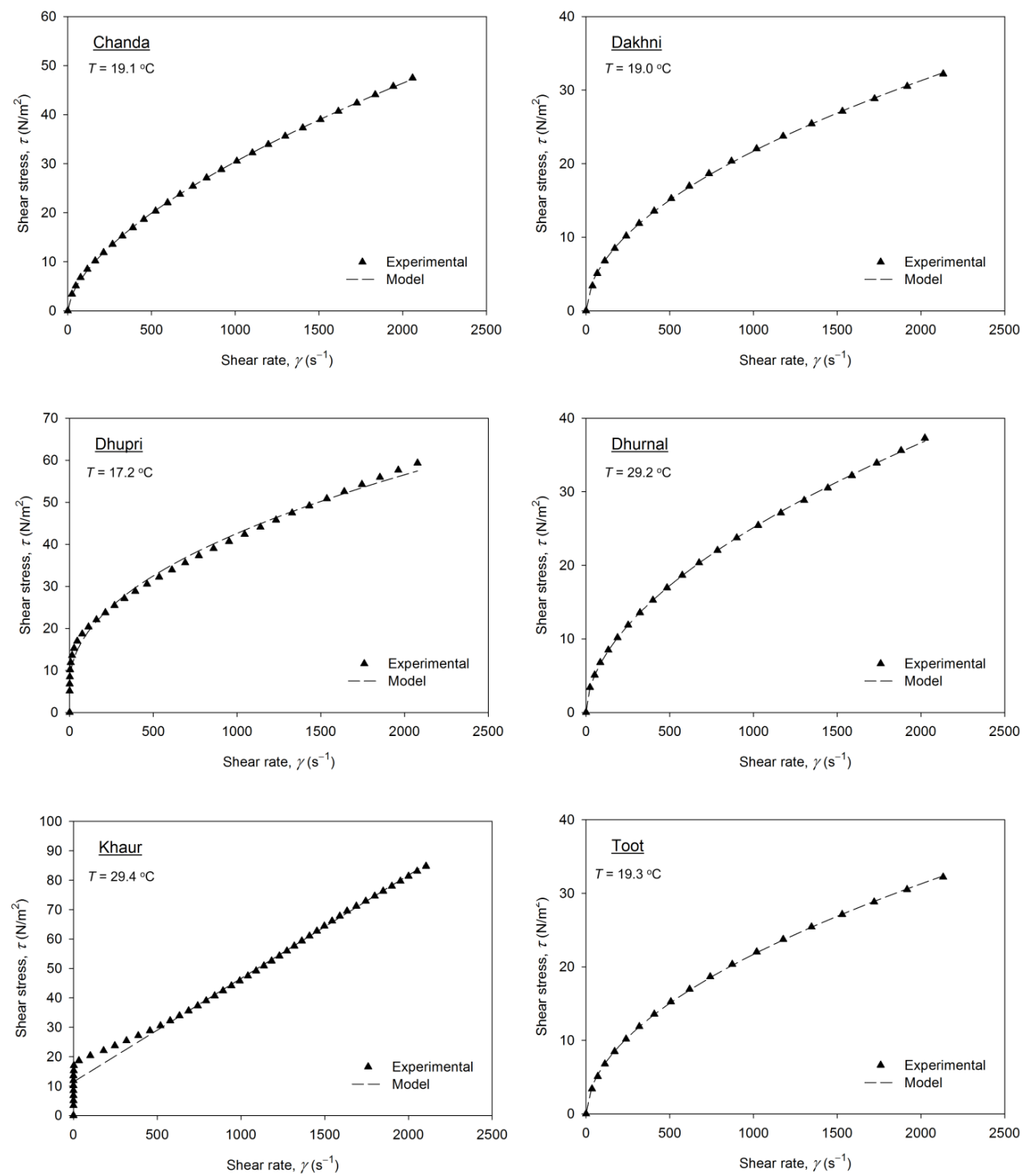

Figure 3. Experimental and model rheograms of various crude oils of Pakistani origins.

Obj.fn $=\frac{S S E}{1000}=\frac{1}{1000} \sum_{i=1}^{i=N}\left(\tau_{i, o b s}-\tau_{i, \text { mod }}\right)^{2}$

Where SSE is the sum of the squares of errors. The $o b j$. fn. (objective function), $R^{2}$, and F-values were used to discriminate among the competitive models. The SigmaPlot software was used to do the regression of the data, automatically calculating $S S E, \mathrm{R}^{2}$, and F-value.

Since the power law or Oswald de Waele model can represent pseudoplastic fluids, the experimental data of shear stress and shear rate of the Chanda, Dakhni, Dhurnal, and Toot crudes were fitted using the power law model given in Table 4.
The power law model was also tried with the Dhupri and Khaur crude oils. As expected, the data of these two crudes did not fit satisfactorily by the power law model and values of $R^{2}$ were found as 0.9790 and 0.9476 , respectively. The low values of $\mathrm{R}^{2}$ together with the shape of the curves in Figure 3 suggested that the Bingham plastic and HerschelBulkley models could be used with the experimental data of Dhupri and Khaur crudes. Visual observation of the curves in Figure 3 indicated that the Dhupri crude followed the Herschel-Bulkley model, whilst the Khaur crude followed the Bingham plastic model. When the Herschel-Bulkley model was used with the Dhupri crude, the $R^{2}$ value reached to 0.9908 whereas by using the Bingham plastic model, the $R^{2}$ value was only 0.9300 . Both Bingham plastic and Herschel- 

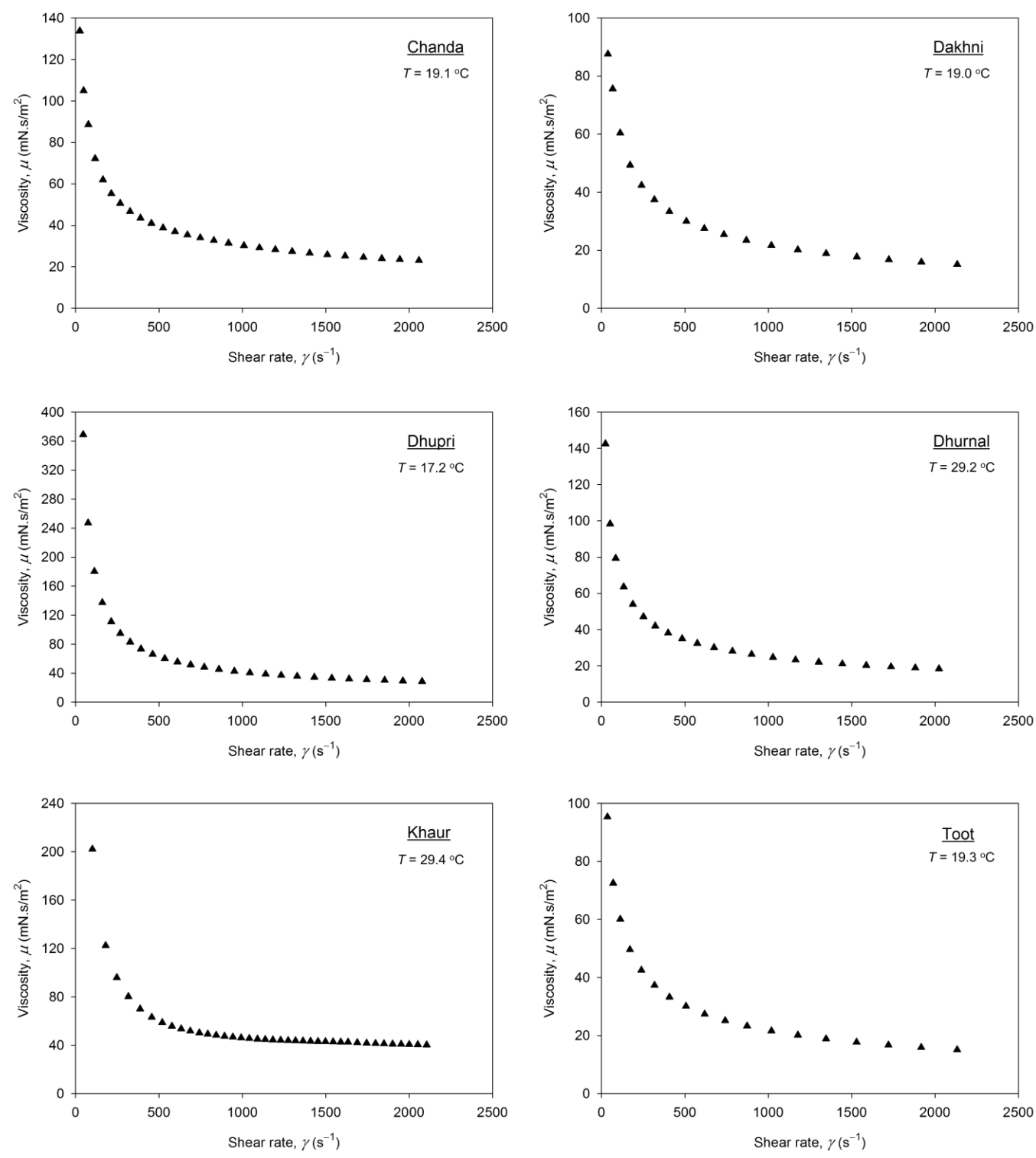

Figure 4. Variation of apparent viscosity with shear rate for various crude oils of Pakistani origins.

Bulkley models were also tried with the Khaur crude oil. Values of $R^{2}$ improved significantly over the power law fitting, and virtually the same $R^{2}$ values were obtained in both cases. However, Fstatistics suggested that the Bingham plastic model was the right model for the Khaur crude oil. The Fvalue for the Bingham plastic model $(F=3285.4)$ was nearly twice as that obtained for the HerschelBulkley model $(F=1693.3)$. This result disallowed the three-parameter Herschel-Bulkley model as the best-fit model, considering that the F-value for the two-parameter model (Bingham model) was substantially decreased upon introducing the third parameter $(n)$. The inclusion of the third parameter in the Bingham model was therefore not justified.
These results confirmed that, under experimental conditions, the Dhupri crude oil followed the Herschel-Bulkley model, and the Khaur crude oil followed the Bingham plastic model. The results of regression, i.e., model parameters along with the corresponding statistics for each crude oil are shown in Table 5 and the rheograms based on the model values are shown in Figure 3. It is important to note that both Dhupri and Khaur crude oils are medium crude oils as shown in Table 3 while all other crude oils that have shown power law behavior are light crude oils.

For the fluids obeying the power law model, all power law indexes were found to be less than 1.0, 
Table 4. Various non-Newtonian models used in the present study.

\begin{tabular}{ccc}
\hline Model & Equation & $\begin{array}{c}\text { Model parameters to be } \\
\text { fitted }\end{array}$ \\
\hline Power law (Oswald de Waele) & $\tau=K \gamma^{n}$ & $K$ and $n$ \\
Herschel-Bulkley & $\tau=K \gamma^{n}+\tau_{0}$ & $K, n$, and $\tau_{0}$ \\
Bingham plastic & $\tau=\mu_{p} \gamma+\tau_{0}$ & $\mu_{p}$ and $\tau_{0}$ \\
\hline
\end{tabular}

Table 5. Results of regression.

\begin{tabular}{ccccccccc}
\hline $\begin{array}{c}\text { Crude } \\
\text { oil }\end{array}$ & $K$ & $n$ & $\mu_{p}$ & $\tau_{0}$ & Obj. fn. & $\mathrm{R}^{2}$ & $\mathrm{~F}$ & Model \\
\hline Chanda & $0.45 \pm 0.01$ & $0.61 \pm 0.00$ & - & - & 0.0006 & 0.9999 & 229101.8 & Power law* \\
Dakhni & $0.57 \pm 0.01$ & $0.53 \pm 0.00$ & - & - & 0.0004 & 0.9997 & 61338.00 & Power law* \\
Dhupri & $1.60 \pm 0.26$ & $0.45 \pm 0.02$ & - & $5.58 \pm 0.75$ & 0.0949 & 0.9908 & 1729.963 & Herschel-Bulkley \\
Dhurnal & $0.59 \pm 0.01$ & $0.54 \pm 0.00$ & - & - & 0.0004 & 0.9999 & 136378.2 & Power law* \\
Khaur & - & - & $0.04 \pm 0.00$ & $11.40 \pm 0.70$ & 0.4327 & 0.9856 & 3285.423 & Bingham plastic \\
Toot & $0.56 \pm 0.01$ & $0.53 \pm 0.00$ & - & - & 0.0003 & 0.9998 & 94034.30 & Power law*
\end{tabular}

*The values of $n<1.0$ have shown that power model is representing pseudoplastic behavior.

which validates pseudoplastic (shear thinning) behavior of the crudes and suggests that the apparent viscosity of these crudes decreases with a shear rate increase (Doran 2003). A relatively higher value, though not to a great extent, for Chanda crude oil suggests it to be less shear thinning among the other three crudes, which virtually have the same power law index value. Since a higher value of consistency index (apparent viscosity for unit shear rate) means higher viscosity and vice versa, the Chanda crude oil was found to be less viscous than the other three crude oils.

\section{CONCLUSIONS}

Six Pakistani crude oils were characterized and various physical properties and product distributions of the crude oils were worked out based on the TBP distillation data and density of the whole crude oil. The rheological properties of the crude oils were experimentally measured and all crude oils were found to be non-Newtonian in nature. Four of the six crude oils proved to be pseudoplastic (obeying the power law model). The Chanda crude oil was the least shear thinning, with the lowest apparent viscosity among the four pseudoplastic crudes. Both Dhupri and Khaur crude oils exhibited yield stress, although the Dhupri crude oil followed the Herschel-Bulkely model and the Khaur crude oil followed the Bingham plastic model.

\section{ACKNOWLEDGEMENTS}

The authors greatly acknowledge OGDCL for providing the crude oil samples and the necessary data. 


\section{NOMENCLATURE}

$C A B P$ - cubic average boiling point, $\mathrm{K}$

$\mathrm{CH}$ - Carbon to hydrogen weight ratio

$\mathrm{Cl}$ - Correlation index

$H C$ - hydrogen to carbon atomic ratio

$i-i$ th value

$K$ - consistency index, Pa. $\mathrm{s}^{\mathrm{n}}\left(\mathrm{kg} \cdot \mathrm{m}^{-1} \cdot \mathrm{s}^{\mathrm{n}-2}\right)$

$K_{W}$ - Watson characterization factor

$M$ - molecular weight, kg. $\mathrm{kmol}^{-1}$

$M A B P$ - molal average boiling point, $\mathrm{K}$

$M e A B P$ - mean average boiling point, $\mathrm{K}$

$n$ - power law index

$N$ - number of data points

$(N B P)_{i}$ - normal boiling point of an ith pseudocomponent, $\mathrm{K}$

$S G$ - specific gravity at $15.6^{\circ} \mathrm{C} / 15.6^{\circ} \mathrm{C}\left(60^{\circ} \mathrm{F} / 60^{\circ} \mathrm{F}\right)$

$T$ - temperature of measurement, $\mathrm{K}$

$x_{i}$ - mole fraction of an ith pseudocomponent

$x_{v i}$ - volume fraction of an ith pseudocomponent

$\nu$ - shear rate, $\mathrm{s}^{-1}$

$\mu_{p \text { - }}$ plastic viscosity, Pa.s

$v$ - kinematic viscosity, cSt

$\rho$ - density, kg. $\mathrm{m}^{-3}$

$\tau$ - shear stress, $\mathrm{Pa}$

$\tau_{0}$ - yield stress, $\mathrm{Pa}$

$\tau_{\text {i,obs }}$ - ith observed or experimental shear stress, $\mathrm{Pa}$

$\tau_{i, \text { mod }}$ - ith model or calculated shear stress, $\mathrm{Pa}$

\section{REFERENCES}

Behrenbruch, P.; Dedigama, T. Classification and characterisation of crude oils based on distillation properties. Journal of Petroleum Science and Engineering, v. 57, p. 166-180, 2007. http://dx.doi.org/10.1016/j.petrol.2005.10.016
Chang, A. F.; Pashikanti, K; Liu, Y. A. Refinery engineering: Integrated process modeling and optimization. Wiley VCH, 2012. http://dx.doi.org/10.1002/9783527666836

Dealy, J. M. Rheological properties of oil sand bitumens. Canadian Journal of Chemical Engineering, v. 57, p. 677-683, 1979. http://dx.doi.org/10.1002/cjce.5450570604

Doran, P. M. Bioprocess engineering principles. $2^{\text {nd }}$ ed. Academic Press, 2013.

Fahim, M. A.; AlSahhaf, T. A.; Elkilani, A. Fundamentals of petroleum refining. Elsevier, 2010.

Ghannam, M. T.; Hasan, S.W.; Abu-Jdayil, B.; Esmail, N. Rheological properties of heavy \& light crude oil mixtures for improving flowability. Journal of Petroleum Science and Engineering, v. 81, p. 122-128, 2012.

http://dx.doi.org/10.1016/i.petrol.2011.12.024

Hameida, A. M. Rheological behavior of Saudi crude oil. Journal of King Saud University, v. 2, p. 181-194, 1990.

Riazi, M. R. Characterization and properties of petroleum fractions. ASTM, 2005.

http://dx.doi.org/10.1520/MNL50 1ST-EB

Speight, J. G. The chemistry and technology of petroleum. $5^{\text {th }}$ ed. CRC Press, 2014.

Zhang, J-J.; Liu, X. Some advances in crude oil rheology and its application. Journal of Central South University of Technology, v. 15, p. 288-292, 2008. http://dx.doi.org/10.1007/s11771-008-0365-4 